Article

\title{
Physicochemical Characterization of Horizontal Directional Drilling Residuals
}

\author{
Joshua Daniel ${ }^{1}$, Chad Penn ${ }^{2, *}$, João Antonangelo ${ }^{1}\left[\right.$ and Hailin Zhang ${ }^{1}(\mathbb{D}$ \\ 1 Plant and Soil Sciences Department, Oklahoma State University, Stillwater, OK 74075, USA; \\ josh.daniel14@gmail.com (J.D.); joao.antonangelo@okstate.edu (J.A.); hailin.zhang@okstate.edu (H.Z.) \\ 2 USDA Agricultural Research Service, National Soil Erosion Research Laboratory, 275 South Russell Street, \\ West Lafayette, IN 479072077, USA \\ * Correspondence: chad.penn@usda.gov; Tel.: +1-765-494-0330
}

Received: 27 August 2020; Accepted: 16 September 2020; Published: 18 September 2020

\begin{abstract}
Horizontal directional drilling (HDD) is a trenchless technology mainly used for the installation of gas, sewer lines, and fiber optic cables. Spent HDD fluid is a by-product of the boring process. However, little is known of its constituency, although the land application of spent HDD residuals would be an economical and less time-consuming method of disposal. Physicochemical analysis of spent HDD residuals from broad geographic regions was conducted to determine if the land application would be an environmentally safe option for disposal. Fifty-eight HDD samples were collected from 26 states throughout the United States. After separation of the liquid and solid portion, the materials were assessed for carbon $(\mathrm{C})$, nitrogen $(\mathrm{N})$, plant nutrients, soluble and total trace metals, total dissolved solids, sodium adsorption ratio (SAR), and potential "leachable metals". All trace metal concentrations in the digested solid portion were well below the limits for biosolids set by the EPA 40 Part 503 rule for land application. Metal concentrations did not exceed the limits of drinking water standards. Besides the total amount of solids, there was nothing chemically limiting HDD residuals from land application. However, if boring through soil with suspected contamination, testing the residual before the application is recommended.
\end{abstract}

Keywords: residuals; horizontal directional drilling; industrial by-products; metals; synthetic precipitation leaching procedure; land application

\section{Introduction}

A wide variety of waste materials and by-products have been land-applied as soil amendments to improve soil quality for centuries [1]. Many by-products are applied as a means of waste disposal. Often the sources of these waste residuals are agricultural, municipal, and industrial wastes or by-products. These materials, in their broadest sense, vary widely in terms of their overall beneficial and environmental impacts. Information acquired over years of research suggests that sustainable land application systems can be established and maintained under a wide range of conditions [2]. Because of environmental concerns and economic restraints in regards to landfilling and incineration, public interest in land application of waste is continuing to grow [3]. As the interest in land application increases so does public speculation on potential contaminants added to the land. Perhaps the most important factor in regards to the land application of agricultural, municipal, and industrial by-products is earning the public's trust concerning safety. Gaining the public's trust will require waste management in such a way that protects human and animal health as well as safeguards soil and water resources, and maintains a quality ecosystem for the long term [4].

An industrial by-product with a growing need for disposal is the spent drilling fluid from the oil and natural gas industry. The chemical makeup and physical properties of drilling mud constitute 
its potentially hazardous nature and ability to impact the environment [5]. Drilling muds generally contain bentonite clays, synthetic organic polymers, production water, barite, formation cuttings, and salts [6], but may have other constituents such as petroleum hydrocarbons, heavy metals, and high salt or sodium. The land application or disposal of spent oil and gas drilling fluid is regulated by state regulatory agencies.

The horizontal directional drilling (HDD) industry is on the rise worldwide. In North America alone, the number of drilling units grew from 12 units in 1984 to more than 2000 units in 1995 [7], and this number has only continued to grow over the last 25 years $[8,9]$. The directional drilling market in Europe occupies the third position in the industry, after the US and Africa, although it leads the market as far as drilling operations for telecommunication tools are concerned. This is probably a consequence of European government regulations regarding oil and gas field developments being highly strict. In the last decade, the European Union (EU) Parliament approved a new law on the safety of oil and gas operations in which oil and gas companies have to submit a special report on possible hazards before commencing any drilling operations in EU waters. Horizontal directional drilling is a trenchless technology and its popularity is likely a direct result of its noninvasive nature and reduced project costs $[10,11]$. It is usually used for the installation of underground utilities for municipalities ranging from $50 \mathrm{~mm}$ utility conduits to $900 \mathrm{~mm}$ sewer [10]. Spent HDD residuals are an 'industrial' by-product resulting from the drilling or boring process, which utilizes drilling fluid. Drilling fluids are used in the boring process as a means to stabilize the borehole, float cuttings to the surface, and keep the bit cool. Once the drilling fluid's density reaches $1.078-1.198 \mathrm{mg} \mathrm{mL}^{-1}\left(9-10 \mathrm{lbs}_{\text {gallon }}{ }^{-1}\right.$ ) it is no longer viable and needs to be disposed of [12]. At that point, the by-product is known as "mud" or "residual". The HDD residual constituents are usually water, bentonite (montmorillonite), and/or polymers [12-14], as well as surfactants and soda ash when needed. These additives may or may not be added to aid in the drilling process, depending on the type of soil that is being drilled through. The regulations and bylaws for the proper disposal of the spent HDD residuals vary by municipality as well as by state and are not federally regulated. In Oklahoma, the Corporation Commission (OCC) is the regulating authority for disposal. While most states possess strict rules for the disposal of oil and gas drilling residuals, no regulations or guidelines are currently available for HDD residuals.

Horizontal directional drilling residual containment and disposal is a growing issue, as the number of directional drilling rigs is on the rise paired with the stigma of its association with spent oil and gas drilling mud [10]. Today there is growing speculation about HDD residuals and the safety of their constituents or chemical makeup. As stated above, it is often mistaken for oil and gas drilling mud even though the two by-products are very different. The HDD residuals are simply subsoils mixed with some additives originally used in the drilling fluid. There is a need to separate the public's perception of the spent HDD drilling residuals from that of the oil and gas industry. To date, there is no published research on the chemical and physical makeup of spent HDD residuals or their environmental impact when applied on land. Thus, the objective of this research is to collect and fully characterize many HDD residuals from multiple locations in the United States in order to make an overall assessment of their suitability for land application.

\section{Materials and Methods}

\subsection{HDD Residual Sample Collection and Preparation}

For a broad overall characterization of HDD residuals, it was necessary to obtain samples from multiple locations where HDD operations took place. To do this, packages were sent to contractors throughout the country. These packages contained sample bottles, instructions on how to obtain a representative sample, by fulfilling the proper containers ( $1 \mathrm{~L}$ plastic bottles) with mud, and a written survey. A representative HDD residue sample was considered by either completely filling the sample bottle with mud over an extended period of time as it flows out of the borehole throughout the drilling job or taking samples directly from the ditch or "pit" shortly after the job is complete. Fifty-eight as-is 
samples were received representing 26 US states across the US (Figure 1). Solid content (gravimetric) was determined by shaking samples for $20 \mathrm{~min}$ followed by subsampling and placement in an oven at $65^{\circ} \mathrm{C}$ for $24 \mathrm{~h}$. To conduct several analyses, the solid and liquid portion was separated by centrifugation at $5000 \mathrm{rpm}$ for $10 \mathrm{~min}$ followed by filtration with a Whatman \#41 paper. Since the as-is materials were normally occurring as slurries, presenting a wide range of moisture $\mathrm{w} / \mathrm{w}$ and the solid contents ranging from 0.04 to $0.72 \mathrm{~g}$ solid $\mathrm{g}$ total slurry $^{-1}$, it was more appropriate to perform the physicochemical analyses of samples in both conditions separated solid and water portions and discuss them separately.

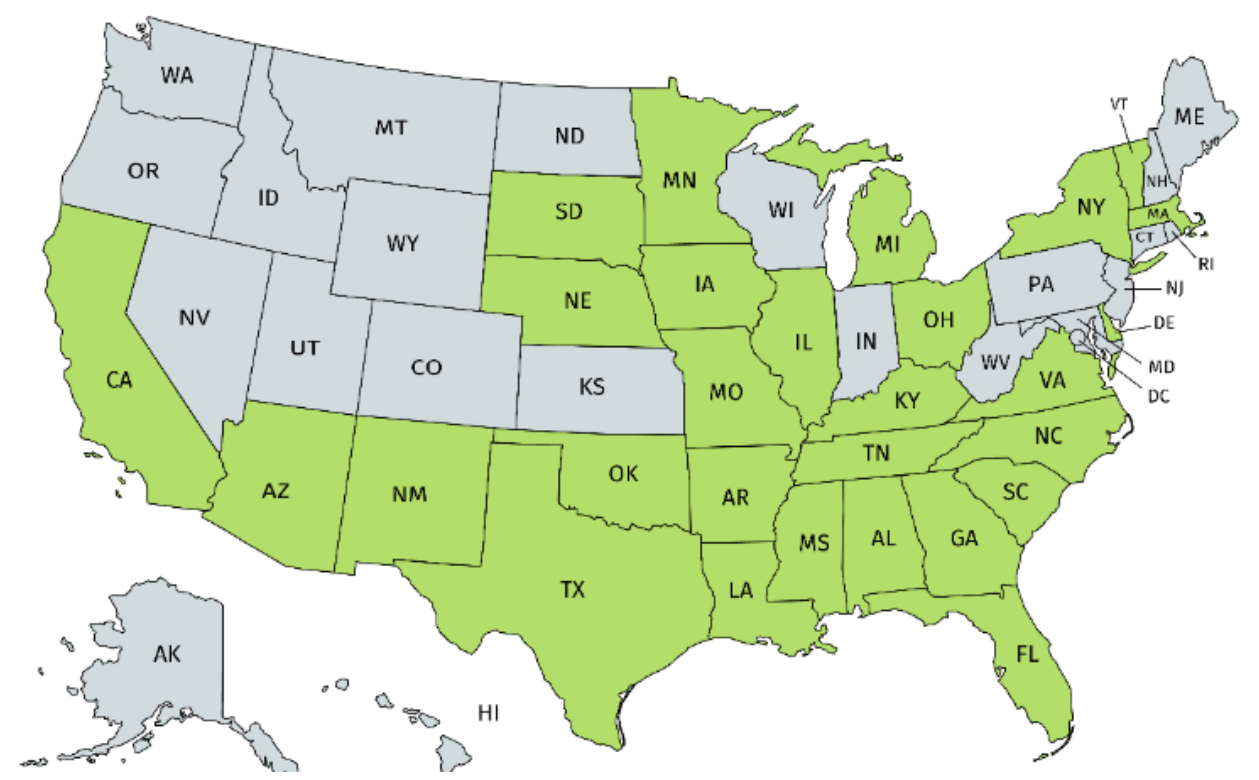

Figure 1. The US States where horizontal directional drilling (HDD) residues were collected (green).

\subsection{Analysis of Separated Solids Fraction}

Two grams of solids were digested using EPA 3050 method (Environmental Protection Agency, EPA 1996) in trace metal grade nitric acid $\left(\mathrm{HNO}_{3}\right)$ and trace metal grade hydrochloric acid $(\mathrm{HCl})$, and $30 \%$ hydrogen peroxide solution. The digests were filtered using Whatman \#41 paper and brought to volume with deionized (DI) water in $50 \mathrm{~mL}$ volumetric flasks, and analyzed for various elements, including aluminum $(\mathrm{Al})$, sodium $(\mathrm{Na})$, sulfur $(\mathrm{S})$, calcium $(\mathrm{Ca})$, magnesium $(\mathrm{Mg})$, phosphorus $(\mathrm{P})$, boron $(\mathrm{B})$, barium $(\mathrm{Ba})$, potassium $(\mathrm{K})$, chromium $(\mathrm{Cr})$, manganese $(\mathrm{Mn})$, iron $(\mathrm{Fe})$, cobalt $(\mathrm{Co})$, nickel $(\mathrm{Ni})$, copper $(\mathrm{Cu})$, zinc $(\mathrm{Zn})$, cadmium $(\mathrm{Cd})$, arsenic $(\mathrm{As})$, and lead $(\mathrm{Pb})$, using an Inductively Coupled Plasma Atomic Emission Spectroscopy (ICP-AES). The results were compared to the EPA Regional Residential Screening Levels (EPA, 2013) as well as EPA 40 CFR 503 Criteria for Exceptional Quality Biosolids (EPA 2007).

Plant-available nutrients $\mathrm{P}, \mathrm{K}, \mathrm{Ca}$, and $\mathrm{Mg}$ were extracted from the separated solids fraction with Mehlich-3 $\left(0.2 \mathrm{M} \mathrm{CH}_{3} \mathrm{COOH}+0.015 \mathrm{M} \mathrm{NH}_{4} \mathrm{~F}+0.013 \mathrm{M} \mathrm{HNO}_{3}+0.001 \mathrm{M}\right.$ EDTA $\left.+0.25 \mathrm{M} \mathrm{H}_{4} \mathrm{NO}_{3}\right)$ at a ratio of 1:10 solids:solution for five minutes, followed by filtration with Whatman \#42 filter paper and analysis by ICP-AES [15]. Total $\mathrm{N}$ and carbon (C) were quantified on the separated solids fraction using LECO TruSpec CN Analyzer (Leco Corporation, St. Joseph, MI, USA).

A modified version of the synthetic precipitation leaching procedure (SPLP) was also performed on the solid portion to simulate potential leachability to groundwater [16]. Extraction solution was made with DI water acidified to a $\mathrm{pH}$ of 4.2 using a 60:40 ratio solution of trace metal grade nitric acid $\left(\mathrm{HNO}_{3}\right)$ to reagent-grade sulfuric acid $\left(\mathrm{H}_{2} \mathrm{SO}_{4}\right)$. Solids were extracted at a 1:20 solid to solution mass ratio for $18 \mathrm{~h}$, followed by centrifugation at $5000 \mathrm{rpm}$ for $10 \mathrm{~min}$ and filtration through $0.45 \mu \mathrm{m}$ glass fiber filters using vacuum filtration. Extracts were analyzed for $\mathrm{Mo}, \mathrm{Al}, \mathrm{B}, \mathrm{Na}, \mathrm{S}, \mathrm{Ca}, \mathrm{Mg}, \mathrm{P}, \mathrm{K}, \mathrm{Cr}, \mathrm{Mn}$, $\mathrm{Fe}, \mathrm{Co}, \mathrm{Cu}, \mathrm{Zn}, \mathrm{Cd}, \mathrm{As}$, and $\mathrm{Pb}$ by ICP-AES. 


\subsection{Analysis of Separated Liquid Fraction}

The separated liquid portion was analyzed for Mo, Al, B, Na, S, Ca, Mg, P, K, Cr, Mn, Fe, Co, $\mathrm{Cu}, \mathrm{Zn}, \mathrm{Cd}, \mathrm{As}$, and $\mathrm{Pb}$ by ICP-AES. This is referred to as "water-soluble" contents. Results were compared to EPA Aquatic Life Criteria Table (EPA 2013). Sodium adsorption ratio was calculated for each sample as the following: (SAR $=\mathrm{Na} / \sqrt{ }((\mathrm{Ca}+\mathrm{Mg}) / 2))$, where $\mathrm{Na}, \mathrm{Ca}$, and $\mathrm{Mg}$ are in units of meq $\mathrm{L}^{-1}$. Electrical Conductivity (EC) and $\mathrm{pH}$ were tested on both HDD residual conditions, the as-is and the separated water portion, using standard $\mathrm{EC}$ and $\mathrm{pH}$ meters.

\subsection{Quality Control}

The analyses of the 58 samples included laboratory check samples for quality assurance and quality control (QA/QC). Reagent blanks and reference samples were analyzed every nine samples. Acceptable recoveries for the certified references were $\pm 10 \%$ of certified values. If a check sample failed control limits, then the nine samples analyzed before and after the failure were reanalyzed. Reference samples from the North American Proficiency Testing Program (NAPTP) were utilized for QA/QC of pH, Mehlich-3 P, K, Ca, and Mg, DC, total C, and total N. Certified biosolids-treated reference soil (CRM005-050, RTC Corp., Laramie, WY, USA) was included in the determination of the total element contents in the liquid and solid portions of HDD residuals. Acceptable method blank concentrations of all elements analyzed were below the established instrumental Limits of Detection (LOD), and the LOD of metals were in the range of 0.1 to $0.2 \mathrm{mg} \mathrm{L}^{-1}$.

\subsection{Statistical Analysis}

A descriptive statistical analysis was performed using Microsoft Excel (2013). Mean, median, minimum, maximum, and standard deviation were calculated for some elements of interest from the extraction methods listed above. The same parameters were also calculated for total C and N, pH, EC, solid content, and sodium adsorption ratio (SAR).

\section{Results}

\subsection{Chemical Properties of HDD Residuals}

Solid content had a broad range of $0.04-0.72$ gr solid g slurry $^{-1}$ with mean and median values of 0.35 and $0.34 \mathrm{~g}$ solid g total slurry ${ }^{-1}$, respectively (Table 1 ). This wide range is likely due to the variability of the original drilling fluid used and the various formations or sub-soils being bored through; for example, sometimes only water is used, without bentonite clay. The electrical conductivity of the residuals ranged from a low of $118 \mu \mathrm{S} \mathrm{cm}{ }^{-1}$ to a high of $3950 \mu \mathrm{S} \mathrm{cm} \mathrm{cm}^{-1}$ with mean and median values of 1198 and $1124 \mu \mathrm{S} \mathrm{cm}^{-1}$, respectively (Table 1). All samples were under the threshold of $4000 \mu \mathrm{S} \mathrm{cm}^{-1}$ for salt-sensitive plants [17]. Electrical conductivity and density were used to calculate loading rates of salt for all samples. Using an application rate of 112 metric tons of solids $\mathrm{ha}^{-1}$, the largest loading rate would apply $3723 \mathrm{~kg} \mathrm{ha}^{-1}$ salt. This is well below the limit of $6724 \mathrm{~kg}$ total dissolved solids ha ${ }^{-1}$ allowed by the OCC for the land application of water-base drilling mud from oil and gas exploration (Oklahoma administrative code and register, Title 165:10-7-19). The majority of samples had $\mathrm{pH}$ values similar to that of a typical subsoil, ranging from 4.7 to 9.9 with a mean of 7.5 and a median of 7.6 (Table 1). The high $\mathrm{pH}$ samples were likely indicative of free carbonates, which could occur naturally in subsoils, or from bicarbonate additives in the original drilling fluid. Overall, the residuals were low in total carbon, ranging from $0.09 \%$ to $6.61 \%$ with a mean of 1.42 and a median of 0.51 (Table 1). Nitrogen content ranged from $0.01 \%$ to $0.26 \%$ with a mean and median of 0.04 . Low $\mathrm{C}$ and $\mathrm{N}$ contents were expected, as the majority of the residual is smectitic clay and subsurface (deeper than $1 \mathrm{~m}$ ) soil and cuttings. The lack of $\mathrm{C}$ and $\mathrm{N}$ in the residual makes it of little value as a potential C or $\mathrm{N}$ source if land applied. 
Table 1. Descriptive statistics for electrical conductivity (EC), in $\mu \mathrm{Sm}^{-1}$, and $\mathrm{pH}$ for both the as-is and separated water portion, and percentage of total carbon $(\mathrm{C})$, total nitrogen $(\mathrm{N})$, and the carbon:nitrogen ratio $(\mathrm{C}: \mathrm{N})$ of the solid portion of the residuals. Solid content is expressed as g solid $\mathrm{g}$ total slurry ${ }^{-1}$. $n=58$.

\begin{tabular}{ccccccc}
\hline HDD Residues & Parameter & Mean & Median & Min & Max & Std Dev \\
\hline Residual as-is & Solid Content & 0.35 & 0.34 & 0.04 & 0.72 & 0.2 \\
& EC & 1198 & 1124 & 118 & 3950 & 772 \\
& $\mathrm{pH}$ & 7.5 & 7.6 & 4.7 & 9.9 & 1.2 \\
Solid Portion & Carbon & 1.42 & 0.51 & 0.09 & 6.61 & 1.75 \\
& Nitrogen & 0.04 & 0.04 & 0.01 & 0.26 & 0.04 \\
\multirow{5}{*}{ Water Portion } & C:N & 42.89 & 14.04 & 2.97 & 276.39 & 62.62 \\
& EC & 1439 & 1334 & 241 & 4296 & 848 \\
& $\mathrm{pH}$ & 7.7 & 8 & 4.2 & 10.1 & 1 \\
\hline
\end{tabular}

HDD: horizontal directional drilling. Min: minimum value. Max: maximum value. Std Dev: Standard Deviation.

\subsection{Characterization of the Separated Liquid Portion}

Descriptive statistics of the whole dataset are presented in Table 2. Sodium adsorption ratio (SAR) was determined on the separated liquid portion of every sample. The mean SAR was 13 with a median of 12.5, ranging from 0.5 to 90.2 (Table 2). A soil with a SAR $\geq 13$ is considered sodic at a $\mathrm{pH}>8.5$ and an $\mathrm{EC}<4000 \mu \mathrm{S} \mathrm{cm}{ }^{-1}$. High concentrations of $\mathrm{Na}$ can negatively impact soil structure and compete with the $\mathrm{Ca}$ and $\mathrm{Mg}$ for plant uptake [18]. Thus, depending on the amount of residual land applied, it may or may not cause any problem to the soil because sodium will be diluted once added to the soil. Most soils contain large amounts of $\mathrm{Ca}$ and $\mathrm{Mg}$. If a residual with high SAR is applied in a large quantity on the surface with no incorporation, it could seal the surface, causing it to be physically dispersed. However, the incorporation of such a residual would prevent this problem from occurring.

Table 2. Descriptive statistics for the elemental concentrations, in $\mathrm{mg} \mathrm{L}^{-1}$, and sodium adsorption ratio (SAR) of the separated liquid portion of HDD residual samples. Ceiling concentrations for the EPA Aquatic Life Criteria are shown as a reference. $n=58$.

\begin{tabular}{|c|c|c|c|c|c|c|}
\hline Element & Mean & Median & Min & Max & Std Dev & EPA Aquatic Life Criteria \\
\hline$S$ & 326.8 & 248.2 & 5.2 & 2708.3 & 400.8 & NA \\
\hline $\mathrm{Na}$ & 285.5 & 272.7 & 18.0 & 856.2 & 191.2 & NA \\
\hline $\mathrm{Ca}$ & 47.0 & 27.2 & 0.8 & 584.7 & 80.9 & NA \\
\hline $\mathrm{Fe}$ & 16.9 & 0.4 & $<\mathrm{LOD}$ & 183.1 & 40.8 & NA \\
\hline $\mathrm{Mg}$ & 16.4 & 10.9 & $<\mathrm{LOD}$ & 74.9 & 17.6 & NA \\
\hline $\mathrm{K}$ & 8.4 & 5.2 & 0.7 & 78.2 & 11.4 & NA \\
\hline $\mathrm{Mn}$ & 1.1 & $<$ LOD & $<\mathrm{LOD}$ & 23.4 & 3.3 & NA \\
\hline $\mathrm{P}$ & 0.6 & 0.1 & $<\mathrm{LOD}$ & 26.6 & 3.5 & NA \\
\hline B & 0.2 & 0.1 & $<\mathrm{LOD}$ & 1.5 & 0.3 & NA \\
\hline Mo & 0.1 & $<\mathrm{LOD}$ & $<\mathrm{LOD}$ & 0.6 & 0.1 & NA \\
\hline $\mathrm{Zn}$ & 0.1 & $<$ LOD & $<\mathrm{LOD}$ & 0.3 & 0.1 & 0.12 \\
\hline $\mathrm{Cr}$ & $<\operatorname{LOD} \ddagger$ & $<\mathrm{LOD}$ & $<\mathrm{LOD}$ & 0.5 & 0.1 & 0.57 \\
\hline $\mathrm{Cu}$ & $<$ LOD & $<$ LOD & $<\mathrm{LOD}$ & 0.3 & 0.1 & NA \\
\hline $\mathrm{Cd}$ & $<\mathrm{LOD}$ & $<\mathrm{LOD}$ & $<\mathrm{LOD}$ & 0.2 & NA $\S$ & 0.002 \\
\hline Co & $<\mathrm{LOD}$ & $<\mathrm{LOD}$ & $<\mathrm{LOD}$ & 0.1 & NA & NA \\
\hline As & $<\mathrm{LOD}$ & $<\mathrm{LOD}$ & $<\mathrm{LOD}$ & $<\mathrm{LOD}$ & NA & 0.34 \\
\hline $\mathrm{Pb}$ & $<\mathrm{LOD}$ & $<\mathrm{LOD}$ & $<\mathrm{LOD}$ & $<\mathrm{LOD}$ & NA & 0.065 \\
\hline SAR & 13.0 & 12.5 & 0.5 & 90.2 & 12.8 & NA \\
\hline
\end{tabular}

Min: minimum value. Max: maximum value. Std Dev: Standard Deviation. ${ }^{\ddagger}:$ Limit of Detection. ${ }^{\dagger}:$ USEPA 2014. National Recommended Water Quality Criteria (http://water.epa.gov/scitech/swguidance/standards/criteria/current/ index.cfm\#altable). \$: Not Applicable.

Elemental concentrations measured on the separated liquid portion were also compared to the EPA Surface Water Quality Criteria for Aquatic Life. One to two elements in 11 samples exceeded this criterion. Eight samples exceeded the criteria for $\mathrm{Zn}$ and three for $\mathrm{Cd}$. It is important to note that the 
maximum concentration for $\mathrm{Cd}$ in this criterion was $2.0 \mu \mathrm{g} \mathrm{L}-1$, which is less than the detection limit of the ICP-AES used for quantification. Based on the results of the metals measured in the liquid portion of the residuals, there is no risk of causing aquatic toxicity if the material was accidentally disposed of directly into a surface water body, except for $\mathrm{Zn}$ and $\mathrm{Cd}$ in a few cases. However, such toxicity is unlikely or negligible when the residual is used properly as a soil amendment.

\subsection{Nutrients in the Solid Portion}

Mehlich 3 extractions were performed on the separated solid portion to determine concentrations of $\mathrm{P}, \mathrm{K}, \mathrm{Ca}$, and $\mathrm{Mg}$, potentially available for plant uptake. The $\mathrm{P}, \mathrm{K}, \mathrm{Ca}$, and $\mathrm{Mg}$ concentration from all samples widely ranged, respectively, from <LOD to $274.6,9.2$ to $658.4,181.8$ to 39320 , and 12.7 to $1315 \mathrm{mg} \mathrm{kg}^{-1}$. When compared to the agronomic optimum, mean concentrations for $\mathrm{K}(156.5 \mathrm{mg}$ $\left.\mathrm{kg}^{-1}\right), \mathrm{Mg}\left(438.8 \mathrm{mg} \mathrm{kg}^{-1}\right)$, and Ca (5600 mg kg-1) were sufficient [19], however, P (23.1 $\left.\mathrm{mg} \mathrm{kg}^{-1}\right)$ would be slightly deficient if the residual was solely used as a medium for plant growth instead of as a soil amendment. A mean Ca level of $5660 \mathrm{mg} \mathrm{kg}^{-1}$ suggests that a residual could be a source of that nutrient among soils that are limited in Ca.

\subsection{Metal Contents of the Separated Solids Portion of HDD Residuals}

The solid portion of HDD residuals digested using EPA method 3050 and analyzed for trace metals including $\mathrm{Mn}, \mathrm{Ba}, \mathrm{Cu}, \mathrm{Zn}, \mathrm{Cr}, \mathrm{Ni}, \mathrm{Pb}, \mathrm{Co}, \mathrm{As}$, and $\mathrm{Cd}$ were also submitted to descriptive statistics (Table 3). Metal concentrations were compared to EPA Part 503 (EPA 1994), which regulates the concentrations and loading of metals for land application of biosolids. The criteria for 'Exceptional Quality' (EQ) biosolids are the strictest standards in this regulation, so the land application of EQ biosolids requires no permit and can be applied based on the $\mathrm{N}$ and $\mathrm{P}$ contents of the material only. Metal concentrations in every residual were considerably less than the ceiling level for EQ biosolids (Table 3).

However, it must be considered that the threshold metal EQ limits were determined based on expected bioavailability in the background matrix of organic matter. This is an important difference from the matrix of the residual samples, which are not rich in organic matter, and will, therefore, have an impact on the bioavailability of the metals. Likely, the metal bioavailability of the residual samples will highly vary as a function of the mineralogy of the material. This difference should be taken into consideration when calculating loading rates for land applying HDD residuals. If all residuals examined in this study were land applied at $112 \mathrm{Mg}$ solid ha $^{-1}$ (or 50 tons solid acre ${ }^{-1}$ ) and compared to the EPA cumulative loading rates for biosolids, no samples would exceed the thresholds (Tables 4 and 5). One sample would exceed the EPA annual loading rate for $\mathrm{Cu}$

The concentrations of metals were also compared to the background concentrations found in Oklahoma benchmark soils [21]. Fifteen samples had some elements above these background concentrations, 12 of which were for $\mathrm{Cu}$. Sample concentrations were also compared to typical levels found in soils throughout the United States [20]. Only seven samples were above these levels, all due to $\mathrm{Cu}$ (Table 3). When compared to the EPA Soil Screening Levels for residential soils (Table 3), As concentrations of two samples exceeded the maximum level but were far lower than the levels found in Oklahoma soils [21].

The modified SPLP was also performed on the solid portion of all samples (Table 6). This procedure is used as a means to estimate the leachability of the constituents in a material. Sample concentrations were compared to Maximum Contaminant Levels (MCLs) set by the EPA for drinking water. No samples exceeded the MCLs. Recommendation and implications on the use of the HDD residues are discussed next. 
Table 3. Descriptive statistics for total elemental concentrations measured in solid residual samples, in $\mathrm{mg} \mathrm{kg}^{-1}$. Values shown in comparison to typical levels found in typical soils of the US, benchmark soils in Oklahoma, EPA 503 ceiling concentrations for exceptional quality (EQ) biosolids, and EPA Soil Screening Levels for Residential Soils. $n=58$.

\begin{tabular}{|c|c|c|c|c|c|c|c|c|c|}
\hline Element & Mean & Median & Min & Max & Std Dev & $\begin{array}{l}\text { Typical Levels } \\
\text { in Soil }^{\dagger}\end{array}$ & $\begin{array}{l}\text { Typical Levels in } \\
\text { Oklahoma Soils } \ddagger\end{array}$ & $\begin{array}{l}\text { EPA Ceiling Concentration } \\
\text { for EQ Biosolids } \S\end{array}$ & $\begin{array}{c}\text { EPA SSL for } \\
\text { Residential Soils }\end{array}$ \\
\hline $\mathrm{Ca}$ & 23,836 & 5751 & 192 & 223,986 & 40,310 & NA & NA & NA & NA \\
\hline $\mathrm{Fe}$ & 16,972 & 14,362 & 570 & 51,185 & 11,299 & NA & NA & NA & NA \\
\hline $\mathrm{Al}$ & 12,814 & 10,764 & 2454 & 42,668 & 8960 & NA & NA & NA & NA \\
\hline $\mathrm{Mg}$ & 5565 & 3641 & 102 & 34,074 & 7334 & NA & NA & NA & NA \\
\hline $\mathrm{Na}$ & 2158 & 829 & 51 & 16,221 & 3314 & NA & NA & NA & NA \\
\hline K & 1342 & 1088 & 85 & 6614 & 1209 & NA & NA & NA & NA \\
\hline S & 971.8 & 549 & 19 & 6236 & 1187 & NA & NA & NA & NA \\
\hline $\mathrm{P}$ & 460.6 & 287 & 30 & 5753 & 826.2 & NA & NA & NA & NA \\
\hline $\mathrm{Mn}$ & 301 & 238 & $<\mathrm{LOD}$ & 1606 & 306 & 80-1300 & $27-2165$ & NA & NA \\
\hline $\mathrm{Ba}$ & 105.9 & 57.6 & 9.2 & 974.1 & 142.9 & NA & NA & NA & 5500 \\
\hline $\mathrm{Cu}$ & 66.1 & 11 & $<\mathrm{LOD}$ & 1863 & 252.2 & $6-80$ & $2-33$ & 4300 & NA \\
\hline $\mathrm{Zn}$ & 39.9 & 30.5 & $<\mathrm{LOD}$ & 341 & 46.4 & $17-125$ & $15-142$ & 7500 & 23,000 \\
\hline B & 37 & 31.2 & $<$ LOD & 194.6 & 31.7 & NA & NA & NA & NA \\
\hline $\mathrm{Cr}$ & 16.8 & 13.4 & 1.9 & 100.1 & 15.3 & $7-221$ & $4-70$ & 3000 & 230 \\
\hline $\mathrm{Ni}$ & 11 & 8.5 & $<\mathrm{LOD}$ & 43.3 & 9.4 & $4-55$ & $2-57$ & 420 & 1600 \\
\hline $\mathrm{Pb}$ & 2.4 & $<\mathrm{LOD}$ & $<\mathrm{LOD}$ & 58.4 & 8.3 & $10-84$ & $3-32$ & 840 & NA \\
\hline Co & 2.3 & $<\mathrm{LOD}$ & $<$ LOD & 15.6 & 4.1 & $1-22$ & NA & NA & NA \\
\hline As & $<\mathrm{LOD}^{\#}$ & $<\mathrm{LOD}$ & $<\mathrm{LOD}$ & 1.6 & 0.2 & $4-9$ & $1-34$ & 75 & 0.4 \\
\hline $\mathrm{Cd}$ & $<\mathrm{LOD}$ & $<\mathrm{LOD}$ & $<$ LOD & $<$ LOD & $\mathrm{NA}^{++}$ & $0.06-1.10$ & $0.13-0.80$ & 85 & 70 \\
\hline
\end{tabular}

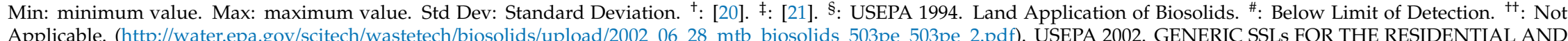
COMMERCIAL/INDUSTRIAL SCENARIOS (http://www.epa.gov/superfund/health/conmedia/soil/pdfs/ssg_appa-c.pdf). 
Table 4. Calculated metal loading rates, in $\mathrm{kg} \mathrm{ha}^{-1}$, for HDD residual samples tested in the study ( 1 to 27), assuming application rates of 112 metric tons solid ha ${ }^{-1}$. Metal loading rates are compared to EPA Cumulative and Annual Pollutant loading rates for biosolids.

\begin{tabular}{cccccccc}
\hline Sample & $\mathbf{Z n}$ & $\mathbf{C u}$ & $\mathbf{N i}$ & $\mathbf{A s}$ & $\mathbf{C d}$ & $\mathbf{C r}$ & $\mathbf{P b}$ \\
\hline 1 & 0.9 & 0.2 & 0.3 & $<$ LOD & $<$ LOD & 3.1 & $<$ LOD \\
2 & 8.2 & 53.6 & 2.2 & $<$ LOD & $<$ LOD & 4.5 & $<$ LOD \\
3 & 3.7 & 1.1 & 1.1 & $<$ LOD & $<$ LOD & 1.5 & $<$ LOD \\
4 & 2.5 & 0.9 & 1.2 & $<$ LOD & $<$ LOD & 2 & 0.1 \\
5 & 7.8 & 5.5 & 3.3 & $<$ LOD & $<$ LOD & 2.8 & 0.1 \\
6 & 5.5 & 3.2 & 2.6 & $<$ LOD & $<$ LOD & 1.9 & $<$ LOD \\
7 & 2 & 1.3 & 0.9 & $<$ LOD & $<$ LOD & 1 & $<$ LOD \\
8 & 2.4 & 1.5 & 0.8 & $<$ LOD & $<$ LOD & 1.8 & 0.5 \\
9 & 1.6 & 16.8 & 0.9 & $<$ LOD & $<$ LOD & 3.8 & $<$ LOD \\
10 & 0.7 & 11.5 & 0.4 & $<$ LOD & $<$ LOD & 2.9 & $<$ LOD \\
11 & 4.8 & 1.6 & 1.8 & $<$ LOD & $<$ LOD & 1.5 & 0.1 \\
12 & 4.6 & 1.6 & 1.8 & $<$ LOD & $<$ LOD & 1.8 & $<$ LOD \\
13 & 1.8 & 2.3 & 0.7 & $<$ LOD & $<$ LOD & 0.7 & $<$ LOD \\
14 & 3.8 & 1.4 & 1.2 & $<$ LOD & $<$ LOD & 2.6 & $<$ LOD \\
15 & 7.1 & 2.6 & 3.2 & $<$ LOD & $<$ LOD & 2.7 & $<$ LOD \\
16 & 4.3 & 2.1 & 1.3 & $<$ LOD & $<$ LOD & 1.3 & $<$ LOD \\
17 & 1.3 & 0.1 & 0.3 & $<$ LOD & $<$ LOD & 1 & 0.9 \\
18 & 1.4 & 0.9 & 0.3 & $<$ LOD & $<$ LOD & 0.9 & 0.4 \\
19 & 2.3 & 0.9 & 1.3 & $<$ LOD & $<$ LOD & 1.2 & $<$ LOD \\
20 & 2.5 & 1 & 1 & $<$ LOD & $<$ LOD & 1 & $<$ LOD \\
21 & 8.4 & 49.7 & 1.8 & $<$ LOD & $<$ LOD & 1.8 & 2.1 \\
22 & 7.9 & 230.2 & 1.7 & $<$ LOD & $<$ LOD & 1.9 & 2.1 \\
23 & 8 & 4.2 & 0.3 & $<$ LOD & $<$ LOD & 0.9 & $<$ LOD \\
24 & 2.3 & 3.7 & 0.2 & $<$ LOD & $<$ LOD & 5.4 & $<$ LOD \\
25 & 3.6 & 2.7 & 1.3 & $<$ LOD & $<$ LOD & 1.4 & $<$ LOD \\
26 & 42.2 & 4.7 & 2.4 & 0.2 & $<$ LOD & 2.2 & 7.2 \\
27 & 3.8 & $<$ LOD & 2.2 & $<$ LOD & $<$ LOD & 12.4 & $<$ LOD \\
EPA Cumulative Pollutant Loading Rate $\S$ & 2800 & 1500 & 420 & 41 & 39 & 3000 & 300 \\
\hline
\end{tabular}

t: Below Limit of Detection. §: USEPA 1994. Land Application of Biosolids. USEPA (http://water.epa.gov/scitech/ wastetech/biosolids/upload/2002_06_28_mtb_biosolids_503pe_503pe_2.pdf).

Table 5. Calculated metal loading rates, in $\mathrm{kg} \mathrm{ha}^{-1}$, for HDD residual samples tested in the study (28 to 58), assuming application rates of 112 metric tons solid ha ${ }^{-1}$. Metal loading rates are compared to EPA Cumulative and Annual Pollutant loading rates for biosolids.

\begin{tabular}{|c|c|c|c|c|c|c|c|}
\hline Sample & $\mathrm{Zn}$ & $\mathrm{Cu}$ & $\mathrm{Ni}$ & As & $\mathrm{Cd}$ & $\mathrm{Cr}$ & $\mathrm{Pb}$ \\
\hline 28 & $<$ LOD + & $<\mathrm{LOD}$ & 0.1 & $<$ LOD & $<\mathrm{LOD}$ & 0.7 & 0.3 \\
\hline 29 & 4 & 4 & 1.6 & $<$ LOD & $<\mathrm{LOD}$ & 2.3 & $<\mathrm{LOD}$ \\
\hline 30 & 1.9 & 1.2 & 0.9 & $<$ LOD & $<\mathrm{LOD}$ & 2.3 & $<\mathrm{LOD}$ \\
\hline 31 & 1.4 & 0.2 & 0.5 & $<$ LOD & $<\mathrm{LOD}$ & 0.7 & $<\mathrm{LOD}$ \\
\hline 32 & 8.6 & 1.2 & 0.8 & $<$ LOD & $<\mathrm{LOD}$ & 1.1 & $<\mathrm{LOD}$ \\
\hline 33 & 1.6 & 1.3 & 0.5 & $<\mathrm{LOD}$ & $<\mathrm{LOD}$ & 0.5 & 0.5 \\
\hline 34 & 12.3 & 4.1 & 0.6 & $<\mathrm{LOD}$ & $<\mathrm{LOD}$ & 0.7 & 1.1 \\
\hline 35 & 0.6 & 0.1 & 0.3 & $<$ LOD & $<\mathrm{LOD}$ & 0.6 & 0.2 \\
\hline 36 & 0.6 & 3.1 & 0.3 & $<\mathrm{LOD}$ & $<\mathrm{LOD}$ & 0.8 & 0.9 \\
\hline 37 & 6.8 & 4.8 & 5.3 & $<$ LOD & $<\mathrm{LOD}$ & 6.1 & $<\mathrm{LOD}$ \\
\hline 38 & 5.7 & 1.4 & 1.3 & $<\mathrm{LOD}$ & $<\mathrm{LOD}$ & 2 & $<\mathrm{LOD}$ \\
\hline 39 & 4.3 & 1.2 & 2.4 & $<$ LOD & $<\mathrm{LOD}$ & 1.8 & 0.8 \\
\hline 40 & 8.1 & 3 & 3.6 & $<\mathrm{LOD}$ & $<\mathrm{LOD}$ & 3.5 & $<\mathrm{LOD}$ \\
\hline 41 & 10.6 & 6.9 & 4.7 & $<\mathrm{LOD}$ & $<\mathrm{LOD}$ & 4.6 & $<\mathrm{LOD}$ \\
\hline 42 & 2.1 & 0.7 & 0.3 & $<\mathrm{LOD}$ & $<\mathrm{LOD}$ & 0.4 & $<\mathrm{LOD}$ \\
\hline 43 & 5.9 & 1.4 & 2.2 & $<\mathrm{LOD}$ & $<\mathrm{LOD}$ & 2.4 & $<\mathrm{LOD}$ \\
\hline 44 & 2.1 & 1 & 0.3 & $<\mathrm{LOD}$ & $<\mathrm{LOD}$ & 0.9 & $<\mathrm{LOD}$ \\
\hline 45 & 6.7 & 0.8 & 1.8 & $<\mathrm{LOD}$ & $<\mathrm{LOD}$ & 0.8 & $<\mathrm{LOD}$ \\
\hline
\end{tabular}


Table 5. Cont.

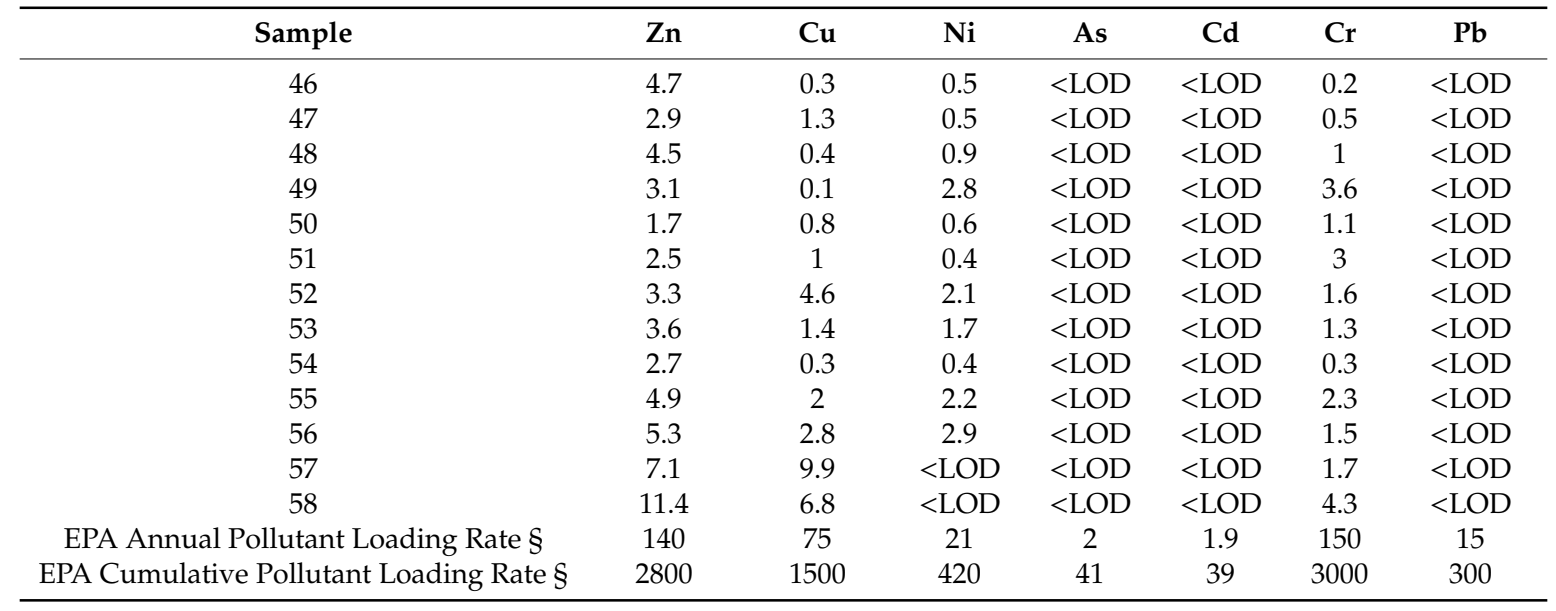

†: Below Limit of Detection. §: USEPA 1994. Land Application of Biosolids. USEPA (http://water.epa.gov/scitech/ wastetech/biosolids/upload/2002_06_28_mtb_biosolids_503pe_503pe_2.pdf).

Table 6. Descriptive statistics for elemental concentrations, in $\mathrm{mg} \mathrm{L}^{-1}$, for analytes from the modified synthetic precipitation leaching procedure (SPLP) performed on the separated solid portion of HDD residuals. Values compared to maximum levels allowed by EPA Drinking Water Criteria. $n=61$.

\begin{tabular}{|c|c|c|c|c|c|c|}
\hline Element & Mean & Median & Min & Max & Std Dev & EPA Drinking Water Criteria ${ }^{\dagger}$ \\
\hline $\mathrm{S}$ & 75.3 & 30.3 & 3.4 & 527.7 & 98.6 & NA \\
\hline $\mathrm{Na}$ & 63.5 & 38.4 & 1.9 & 386.9 & 74.5 & NA \\
\hline $\mathrm{Al}$ & 38.7 & 21.6 & $<\mathrm{LOD}$ & 204.1 & 51.0 & NA \\
\hline $\mathrm{Fe}$ & 15.4 & 9.0 & $<$ LOD & 105.0 & 20.6 & NA \\
\hline $\mathrm{Ca}$ & 12.7 & 7.4 & 0.1 & 239.6 & 30.3 & NA \\
\hline $\mathrm{Mg}$ & 6.3 & 4.1 & $<\mathrm{LOD}$ & 42.1 & 8.4 & NA \\
\hline K & 4.1 & 3.6 & $<\mathrm{LOD}$ & 21.5 & 5.1 & NA \\
\hline B & 0.6 & 0.7 & 0.1 & 1.6 & 0.4 & NA \\
\hline $\mathrm{P}$ & 0.3 & 0.1 & $<\mathrm{LOD}$ & 5.5 & 0.8 & NA \\
\hline Mn & 0.1 & $<\mathrm{LOD}$ & $<\mathrm{LOD}$ & 2.3 & 0.3 & NA \\
\hline $\mathrm{Ba}$ & 0.1 & 0.1 & $<\mathrm{LOD}$ & 0.3 & 0.1 & 2.0 \\
\hline $\mathrm{Cu}$ & $<\mathrm{LOD} \ddagger$ & $<\mathrm{LOD}$ & $<\mathrm{LOD}$ & 2.1 & 0.3 & $1.3^{\#}$ \\
\hline $\mathrm{Zn}$ & $<\mathrm{LOD}$ & $<\mathrm{LOD}$ & $<\mathrm{LOD}$ & 0.2 & 0.1 & NA \\
\hline $\mathrm{Cr}$ & $<\mathrm{LOD}$ & $<$ LOD & $<\mathrm{LOD}$ & 0.1 & $\mathrm{NA}^{\text {II }}$ & 0.1 \\
\hline $\mathrm{Ni}$ & $<\mathrm{LOD}$ & $<\mathrm{LOD}$ & $<$ LOD & 0.2 & NA & NA \\
\hline Mo & $<\mathrm{LOD}$ & $<$ LOD & $<\mathrm{LOD}$ & 0.1 & NA & NA \\
\hline $\mathrm{Co}$ & $<\mathrm{LOD}$ & $<$ LOD & $<\mathrm{LOD}$ & 0.1 & NA & NA \\
\hline As & $<\mathrm{LOD}$ & $<\mathrm{LOD}$ & $<\mathrm{LOD}$ & $<\mathrm{LOD}$ & NA & 0.01 \\
\hline $\mathrm{Cd}$ & $<\mathrm{LOD}$ & $<\mathrm{LOD}$ & $<\mathrm{LOD}$ & $<\mathrm{LOD}$ & NA & 0.005 \\
\hline $\mathrm{Pb}$ & $<\mathrm{LOD}$ & $<$ LOD & $<\mathrm{LOD}$ & $<\mathrm{LOD}$ & NA & $<$ LOD \\
\hline
\end{tabular}

Min: minimum value. Max: maximum value. Std Dev: Standard Deviation. ${ }^{\dagger}$ : USEPA 2014. Drinking Water Contaminants. (https://www.epa.gov/sdwa/drinking-water-regulations-and-contaminants). ‡: Below Limit of Detection. II: Not Applicable. \#: At Tap.

\section{Discussion}

There are typically two criteria used to assess a residual's "suitability" for land application: (i) the by-product's ability to enhance, or have no negative impact, on the productivity of the soil and plant growth, and (ii) a lack of negative environmental impacts [22]. Before land applying HDD residuals, one must consider the in-situ soil or geologic formation being bored through, from which the residuals originated. If boring through a site with known contamination, performing analysis for contaminants, such as heavy metals and salinity, is suggested. This could potentially be a problem when boring through the ground with a historic industrial use. For example, during the industrial revolution, industrial processes such as $\mathrm{Cd}$ plating and $\mathrm{Cu}$ smelting were commonly conducted outside of the major metropolitan areas. These areas are now referred to as suburbs. This is especially true for areas 
along the east coast. If boring takes place in an area where $\mathrm{Cu}$ smelting once occurred, drilling residuals would potentially contain high concentrations of $\mathrm{Cu}$. A quick metal detection technique should be developed for onsite screening before deciding how HDD should be disposed of.

The EPA Part 503 criteria for metals concerning the land application of biosolids can be used as a guide for maximum allowable metals in an HDD residual to be land applied. One key difference between biosolids and HDD residuals is the organic matter content. Because of HDD residuals having low organic content, the bioavailability of metals is something to take into consideration. Because bioavailability differs with plant species [23], having an estimate of free metal concentration may be more useful. Separation by diffusion using the Donnan membrane technique is one method suggested to measure inorganic contaminants, or free metal concentrations, available for plant uptake [24]. Other methods include using the chelating agents' diethylenetriaminepentaacetic acid (DTPA) or ethylenediaminetetraacetic acid (EDTA) to extract potentially bioavailable metals [25]. A study in China used the rhizosphere method, which uses low molecular weight organic acids to extract bioavailable metals, and compared results to the DTPA and EDTA methods. Their results showed the rhizosphere method to be the most robust in predicting the bioavailability of $\mathrm{Cr}, \mathrm{Cu}, \mathrm{Zn}$, and Cd in soils to barley [26]. However, this study showed that the metals contained in the residuals were poorly soluble in water, thus potentially indicating that bioavailability and mobility would also be minimal.

A residual with a high SAR and/or salt concentration could be a problem, especially if the receiving soil is borderline saline and/or sodic. Unlike oil and gas drilling mud, HDD residuals are not going to contain geologic salts or return water from deep formations. However, this does not mean that HDD residuals do not have the potential to have a negative impact. Measuring the EC of an HDD residual before it is land applied would be beneficial in determining whether it could harm the soil that is receiving it. If the SAR of a residual is known to be above 13, incorporating the residual is recommended.

It is not recommended to use HDD residuals solely as a planting medium, although nothing was chemically limiting among the residual samples included in this study that would limit its use as a soil amendment. Total solids were found to be the most limiting factor for land application. Because of the residuals' high clay content, applying too much of an HDD residual could smother the receiving soil and plants, resulting in poor plant growth and minimal water infiltration. If applied at a proper rate, the high clay content could improve sandy soil's ability to retain water and nutrients. To minimize environmental impact to the receiving soil and plant life, acceptable HDD residuals (i.e., low metals and salt concentrations) should be applied at a rate $\leq$ of 112 metric tons solid ha ${ }^{-1}$ on the ground with a slope $\leq 8 \%$ to minimize erosion and loss to surface water. Current regulations for oil and gas drilling residuals in Oklahoma allow for nearly 225 metric tons of solids ha ${ }^{-1}$.

\section{Conclusions}

The physicochemical characterization of liquid and solid HDD residuals was performed on several samples from a broad geographic area in the US and showed that the total solids content was the most limiting factor for HDD residuals application. Despite that, land application proved itself a viable option for HDD residuals disposal, which encourages further studies investigating the impacts of field application of HDD on soils and plants. Faster and non-destructive methodologies for measuring elements in HDD residues, such as metals, are necessary to quickly qualify the materials for land application in the field. Such a technique could be explored with sensor technology that would eliminate the need to digest samples from the HDD residues in the laboratory.

Author Contributions: Conceptualization, J.D. and C.P.; methodology, J.D. and C.P.; validation, J.D, C.P, J.A. and H.Z.; formal analysis, J.D., J.A. and H.Z.; investigation, J.D. and C.P.; resources, C.P. and H.Z.; data curation, J.D., C.P., J.A. and H.Z.; writing-original draft preparation, J.D.; writing—review and editing, J.A.; visualization, J.A.; supervision, C.P.; project administration, C.P. and H.Z.; funding acquisition, C.P. All authors have read and agreed to the published version of the manuscript. 
Funding: This work was supported by the Oklahoma Agricultural Experiment Station.

Conflicts of Interest: The authors declare no conflict of interest.

\section{References}

1. Lederer, J.; Rechberger, H. Comparative goal-oriented assessment of conventional and alternative sewage sludge treatment options. Waste Manag. 2010, 30, 1043-1056. [CrossRef]

2. Bastian, R.K. Interpreting Science in the Real World for Sustainable Land Application. J. Environ. Qual. 2005, 34, 174-183. [CrossRef]

3. Cattle, S.R.; Robinson, C.; Whatmuff, M. The character and distribution of physical contaminants found in soil previously treated with mixed waste organic outputs and garden waste compost. Waste Manag. 2020, 101, 94-105. [CrossRef]

4. Larney, F.J.; Olson, B.M.; Janzen, H.; Lindwall, C. Early Impact of Topsoil Removal and Soil Amendments on Crop Productivity. Agron. J. 2000, 92, 948-956. [CrossRef]

5. Onwukwe, S.I.; Nwakaudu, M.S. Drilling Wastes Generation and Management Approach. Int. J. Environ. Sci. Dev. 2012, 252-257. [CrossRef]

6. Bauder, T.A.; Barbarick, K.A.; Ippolito, J.A.; Shanahan, J.F.; Ayers, P.D. Soil Properties Affecting Wheat Yields following Drilling-Fluid Application. J. Environ. Qual. 2005, 34, 1687-1696. [CrossRef]

7. Kirby, M.J.; Kramer, S.R.; Pittard, G.T. Guidelines for the Application of Guided Horizontal Drilling to Install Gas Distribution Pipe; Gas Research Institute: Chicago, IL, USA, 1996.

8. Krechowicz, M. Comprehensive Risk Management in Horizontal Directional Drilling Projects. J. Constr. Eng. Manag. 2020, 146, 04020034. [CrossRef]

9. Lu, H.; Behbahani, S.; Azimi, M.; Matthews, J.C.; Han, S.; Iseley, T. Trenchless Construction Technologies for Oil and Gas Pipelines: State-of-the-Art Review. J. Constr. Eng. Manag. 2020, 146, 03120001. [CrossRef]

10. Allouche, E.N.; Ariaratnam, S.T.; Lueke, J.S. Horizontal Directional Drilling: Profile of an Emerging Industry. J. Constr. Eng. Manag. 2000, 126, 68-76. [CrossRef]

11. Dong, S.; Zeng, C.; Ariaratnam, S.T.; Ma, B.; Yan, X.; Li, Z.; Li, X. Experimental and performance analysis of reverse circulation reaming in horizontal directional drilling. Tunn. Undergr. Space Technol. 2020, 95, 103128. [CrossRef]

12. Sun, P.; Tian, M.; Cao, H.; Niu, L.; Zhang, S. Study on the mechanism of ENI action on preventing drilling fluid overflowing in HDD. Tunn. Undergr. Space Technol. 2018, 77, 94-102. [CrossRef]

13. Ariaratnam, S.T.; Lueke, J.S.; Anderson, E. Reducing Risks in Unfavorable Ground Conditions during Horizontal Directional Drilling. Pract. Period. Struct. Des. Constr. 2004, 9, 164-169. [CrossRef]

14. Bleier, R. Selecting a Drilling Fluid. J. Pet. Technol. 1990, 42, 832-834. [CrossRef]

15. Hageman, P.L. Synthetic Precipitation Leaching Procedure (SPLP) Leachate Chemistry Data for Solid Mine-Waste Composite Samples from Southwestern New Mexico, and Leadville, Colorado; U.S. Dept. of the Interior, U.S. Geological Survey: Denver, CO, USA, 2000.

16. Pierzynski, G.M.; Vance, G.F.; Sims, J.T. Soils and Environmental Quality; Taylor \& Francis: Boca Raton, FL, USA, 2005.

17. Mehlich, A. Mehlich 3 soil test extractant: A modification of Mehlich 2 extractant. Commun. Soil Sci. Plant Anal. 1984, 15, 1409-1416. [CrossRef]

18. Naidu, R.; Rengasamy, P. Ion interactions and constraints to plant nutrition in Australian sodic soils. Soil Res. 1993, 31, 801. [CrossRef]

19. Zhang, H.; Raun, B. Oklahoma Soil Fertility Handbook; Department of Plant and Soil Sciences, Oklahoma Agricultural Experiment Station, Oklahoma Cooperative Extention Service, Division of Agricultural Sciences and Natural Resources, Oklahoma State University: Stillwater, OK, USA, 2006.

20. McBride, M.B. Environmental Chemistry of Soils; Oxford University Press: New York, NY, USA, 1998.

21. Richards, J.R.; Schroder, J.L.; Zhang, H.; Basta, N.T.; Wang, Y.; Payton, M.E. Trace Elements in Benchmark Soils of Oklahoma. Soil Sci. Soc. Am. J. 2012, 76, 2031-2040. [CrossRef]

22. Whalen, J.K.; Chang, C.; Clayton, G.W.; Carefoot, J.P. Cattle Manure Amendments Can Increase the pH of Acid Soils. Soil Sci. Soc. Am. J. 2000, 64, 962-966. [CrossRef]

23. Kabata-Pendias, A. Soil-plant transfer of trace elements-An environmental issue. Geoderma 2004, 122, 143-149. [CrossRef] 
24. Harmsen, J. Measuring Bioavailability: From a Scientific Approach to Standard Methods. J. Environ. Qual. 2007, 36, 1420-1428. [CrossRef]

25. Wear, J.I.; Evans, C.E. Relationship of Zinc Uptake by Corn and Sorghum to Soil Zinc Measured by Three Extractants. Soil Sci. Soc. Am. J. 1968, 32, 543-546. [CrossRef]

26. Feng, M.-H.; Shan, X.-Q.; Zhang, S.; Wen, B. A comparison of the rhizosphere-based method with DTPA, EDTA, $\mathrm{CaCl} 2$, and $\mathrm{NaNO} 3$ extraction methods for prediction of bioavailability of metals in soil to barley. Environ. Pollut. 2005, 137, 231-240. [CrossRef] [PubMed]

(C) 2020 by the authors. Licensee MDPI, Basel, Switzerland. This article is an open access article distributed under the terms and conditions of the Creative Commons Attribution (CC BY) license (http://creativecommons.org/licenses/by/4.0/). 